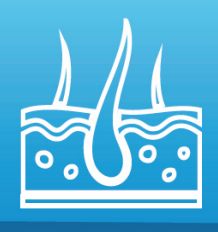

DERMATOLOGY
1) Department of Pathology, Lady Hardinge Medical College, New Delhi, India

2) Core Diagnostics, Gurgaon, India

3) Department of Pathology, Adesh Institute of Medical Sciences and Research, Bathinda, Punjab, India

4) Department of Pathology, Government Medical College and Hospital, Sector 32-A, Chandigarh, India
DOI: $10.15386 / \mathrm{mpr}-1384$

Manuscript received: 05.06.2019

Received in revised form: 05.10.2019

Accepted: 12.01.2020

Address for correspondence:

drharshidhingra@gmail.com

This work is licensed under a Creative Commons Attribution-NonCommercialNoDerivatives 4.0 International License

\section{Clinico-pathological spectrum of cutaneous sarcoidosis: an experience from a government institute in North India}

Priyanka Singh ${ }^{1}$, Ekta Jain ${ }^{2}$, Harshi Dhingra ${ }^{3}$, Harsh Mohan ${ }^{4}$, GP Thami ${ }^{4}$

\begin{abstract}
Background and aims. Sarcoidosis is a multisystem granulomatous disease of unknown etiology and cutaneous involvement is the second most frequent manifestation in systemic sarcoidosis.

The aim of the present study is to evaluate the clinical and pathological spectrum of cutaneous sarcoidosis and compare the same with literature available.

Methods. The present retrospective study was conducted from January 2010-March 2015 and fifteen cases diagnosed as cutaneous sarcoidosis on biopsy were reviewed. The histological spectrum of cutaneous sarcoidosis was evaluated.

Results. The mean age at diagnosis was 46 years. Nine (60\%) cases out of 15 were females. Most common cutaneous lesions were nodules (46.6\%) followed by papules $(40 \%)$. Classically, lymphocyte-poor, non-caseating epithelioid cell granulomas, was the most common histologic finding. Inclusion bodies were seen in $20 \%$ cases with occasional presence of fibrinoid necrosis (13.3\%). Peri-adnexal granuloma, seen in one case, raised the possibility of tuberculoid leprosy. Foreign body was seen in one case supporting the opinion that sarcoidosis and granulomatous foreign body reaction are not mutually exclusive. Epidermal changes including atrophy, loss of rete pegs, acanthosis, papillomatosis, hyperkeratosis, parakeratosis and basal cell vacuolation were seen in $46.6 \%$ cases. Reticulin was positive in all the cases while special stains for acid fast bacilli and fungi were negative.
\end{abstract}

Conclusion. The clinical presentation of cutaneous sarcoidosis may be variable. Presence of naked, reticulin-rich granulomas is the most characteristic histopathological finding. Correlation of clinical history with histologic examination is essential to exclude other granulomatous diseases including leprosy, syphilis, other infectious granulomatous diseases and foreign body reaction.

Keywords: cutaneous sarcoidosis, naked non-caseating granulomas, lymphocyte poor

\section{Introduction}

Sarcoidosis is a granulomatous disorder of unknown etiology that affects multiple organ systems. It may present with a wide range of clinical manifestations most frequently involving lungs, lymph nodes, skin, liver, spleen, eyes and parotid glands [1]. It is more prevalent in females and shows a bimodal age distribution with one peak in the third decade of life and second peak in the fifth decade of life [2-4]. Cutaneous involvement has been reported in approximately $25 \%$ cases and most often occurs at disease onset [5-7].
About $25 \%$ cases of cutaneous sarcoidosis lesions are limited to the face $[8,9]$. It is a diagnosis of exclusion that is made by identifying granulomatous inflammation in the absence of a known infectious or other cause.

Skin lesions in cutaneous sarcoidosis can be classified into specific and nonspecific. The 'specific' lesions reveal collection of epithelioid histiocytes with no or minimal inflammatory cells called as naked sarcoidal granulomas (NSG) or sarcoidal non-caseating granulomas. The 'non-specific' lesions 
include erythema nodosum (most common), calcinosis cutis, prurigo and erythema multiforme [6]. The most common clinical presentation of specific lesions is macules and papules, but plaques, nodules, lupus pernio, subcutaneous infiltrates and infiltration of pre-existing scars are also commonly identified [10-13]. The diagnosis of sarcoidosis is based on clinical, radiologic and histologic evidence of noncaseating granulomas in one or more organ systems with exclusion of other potential diagnosis [6]. There is limited data in the literature on cutaneous sarcoidosis with respect to Indian scenario. Thus, the present study aims to characterize the clinico-pathological features of cutaneous sarcoidosis and compare it with the literature available.

\section{Methods}

The present retrospective study was conducted from January 2010-March 2015 by compiling the data from archival records. The clinical and histopathological features of cutaneous sarcoidosis were evaluated. Clinical charts were retrospectively reviewed to obtain the following data: gender, age at diagnosis, morphology and location of cutaneous lesions, associated symptoms, presence or absence of any extra-cutaneous disease and associated comorbid conditions. The hematoxylin and eosin-stained slides were reviewed in all the patients. Patterns of granuloma localization (superficial dermis, mid-dermis, deep dermis, and subcutaneous fat) and distribution (peri-vascular, peri-adnexal, perineural and interstitial) were examined. Assessment of additional features including the presence of lymphoid cells, multinucleated giant cells, inclusion bodies, necrosis, fibrosis, foreign material and epidermal changes were noted. Special stains like reticulin, acid fast bacilli (AFB), wade-fite stain and periodic acid Schiff (PAS) were performed wherever required to rule out infectious cause.

\section{Ethics approval}

As anonymized patient reports were used, ethical permission was not required for the study.

\section{Results}

The study included fifteen cases, nine $(60 \%)$ females and six (40\%) males, with female to male ratio of $1.5: 1$. The mean age at diagnosis was 46 years (range: 33 to 65 years). Nodules (46.6\%) were the most common morphology of cutaneous lesion, followed by papules $(40 \%)$, plaque $(6.7 \%)$ and cystic swelling (6.7\%) (Table I). The lesions were limited to head and neck (46.7\%), arms $(20 \%)$, back (13.3) and legs (6.7\%). Two patients demonstrated lesions in two or more locations - hand and back and hand, wrist and trunk respectively. Forty six percent of cases showed face involvement. Thirteen percent of cases presented with recurrent forehead swelling. No co-morbid condition was noted in any of the cases.

Table I. Characteristics of the 15 patients with cutaneous sarcoidosis.

\begin{tabular}{|c|c|c|}
\hline Characteristics & $\begin{array}{c}\text { Number } \\
(n=15)\end{array}$ & Percentage \\
\hline \multicolumn{3}{|l|}{ Sex } \\
\hline Male & 6 & 40 \\
\hline Female & 9 & 60 \\
\hline Age in years (mean) & 46 & \\
\hline Range & $33-65$ & \\
\hline \multicolumn{3}{|l|}{ Lesion Morphology } \\
\hline Nodule & 7 & 46.6 \\
\hline Papule & 6 & 40 \\
\hline Plaque & 1 & 6.7 \\
\hline Cystic swelling & 1 & 6.7 \\
\hline \multicolumn{3}{|l|}{ Location } \\
\hline Head \& neck & 7 & 46.7 \\
\hline Arms & 3 & 20 \\
\hline Back/trunk & 2 & 13.3 \\
\hline Leg & 1 & 6.7 \\
\hline Multiple (Lesion at $>2$ sites) & 2 & 13.3 \\
\hline \multicolumn{3}{|l|}{ Symptoms } \\
\hline Asymptomatic & 8 & 53.3 \\
\hline Painful & 4 & 26.7 \\
\hline Pruritic & 3 & 20 \\
\hline Recurrent lesions & 2 & 13.3 \\
\hline \multicolumn{3}{|l|}{ Microscopic findings } \\
\hline NSG & 13 & 86.7 \\
\hline Fibrinoid necrosis & 2 & 13.3 \\
\hline Epithelioid cells & 15 & 100 \\
\hline Giant cells & 15 & 100 \\
\hline Inclusion body & 3 & 20 \\
\hline Epidermal changes & 7 & 46.6 \\
\hline Atrophy & 4 & 26.7 \\
\hline $\begin{array}{l}\text { Other (hyperkeratosis, para- } \\
\text { keratosis, acanthosis, papillomatosis } \\
\text { and basal cell vacuolation }\end{array}$ & 3 & 20 \\
\hline
\end{tabular}

Radiographic findings were available in $13.3 \%$ cases and were within normal limits. Data regarding the laboratory findings including serum angiotensin converting enzyme (ACE) levels and extra-cutaneous manifestation were not available.

Non-caseating, lymphocyte-poor, epithelioid cell granulomas was the predominant finding seen in $86.7 \%$ cases. Fibrinoid necrosis was noted in $13.3 \%$ cases. Distribution of granulomas was noted in both superficial and deep dermis in all the cases (Figure 1 and 2). Granulomas were seen in the subcutaneous fat $(33.3 \%)$, peri-adnexal $(6.7 \%)$ and in perimuscular areas in $(6.7 \%)$ cases. Characteristics of granulomas are described in Table II.

Table II. Characteristics of Granulomas.

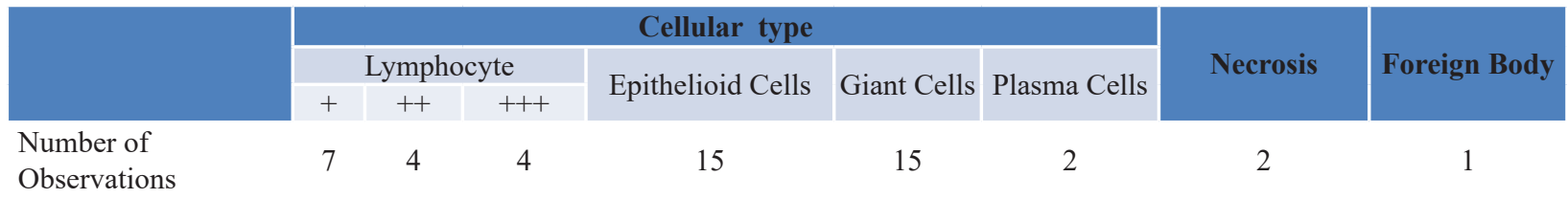


The density of the lymphocytic infiltrate was mild in $46.6 \%$, moderate in $26.7 \%$ and severe in $26.7 \%$. Multinucleated giant cells (mixture of Langhans giant cells and foreign body giant cells) were the most consistent finding seen in all patients, inclusion bodies were seen in $20 \%$ and foreign body seen in $6.7 \%$ cases. Epidermal changes were seen in $46.6 \%$ cases which included epidermal atrophy in $26.7 \%$ and other features included parakeratosis, hyperkeratosis, acanthosis, papillomatosis and basal cell vacuolation. Various special stains including AFB, GroccottGomori stain and Wade-Fite stain were applied to rule out tubercular granuloma, fungal granuloma and leprosy respectively. Reticulin stain applied showed reticulin rich sarcoidal granulomas in $100 \%$ of the cases (Figure 3).

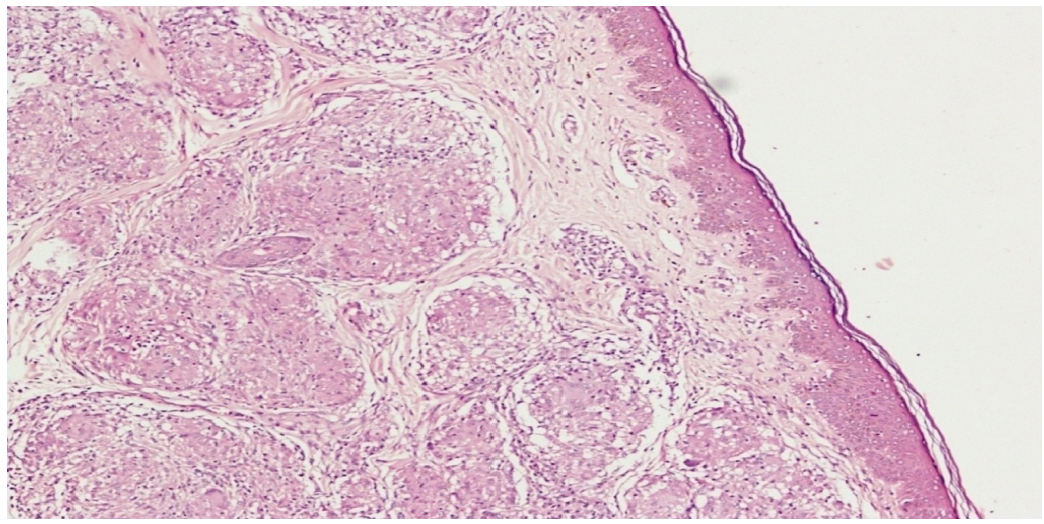

Figure 1. Numerous NSGs in the dermis. Overlying epidermis is atrophied (H\&E x200).

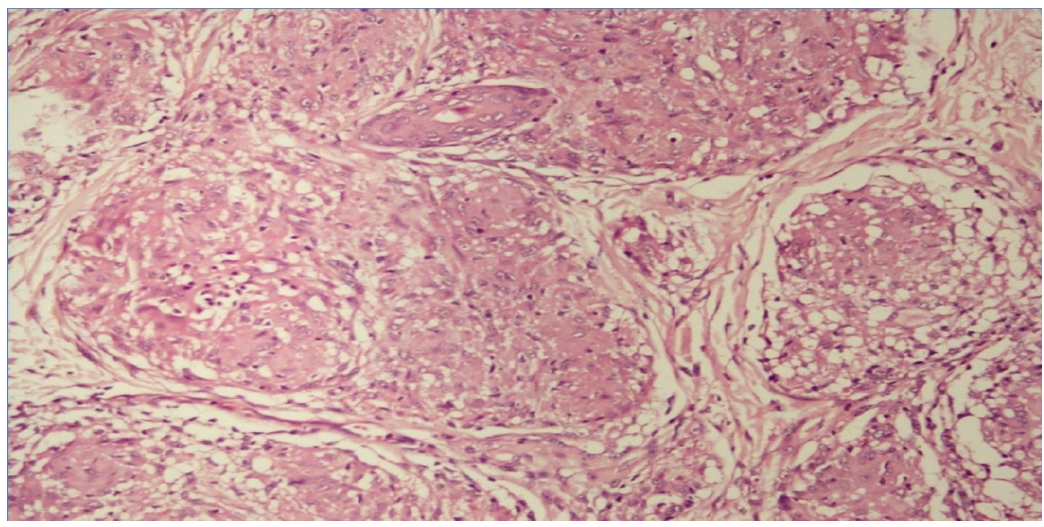

Figure 2. High power showing numerous lymphocyte poor, non caseating epithelioid cell granulomas in dermis (H\&E x600).

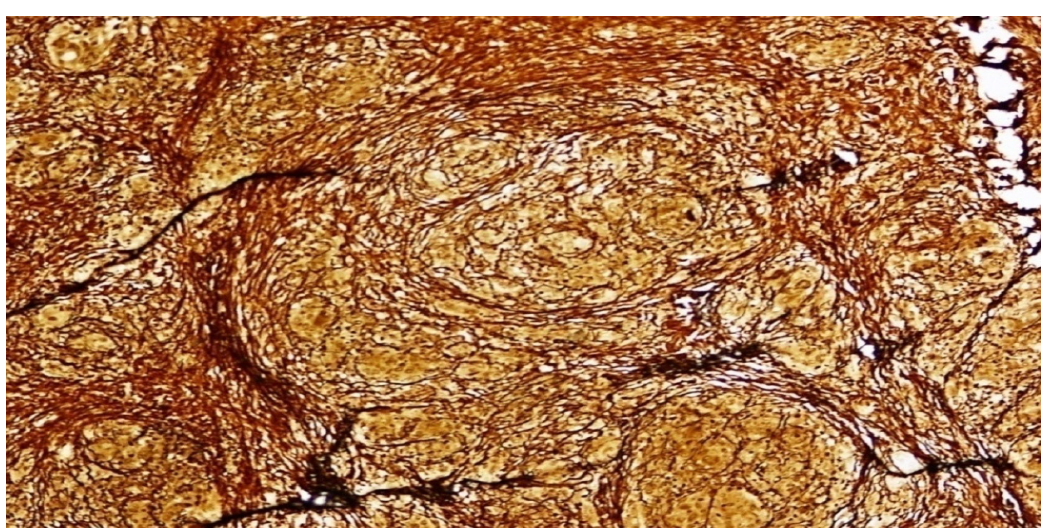

Figure 3. High power view showing reticulin rich sarcoid granulomas (Reticulin x600). 


\section{Discussion}

Skin involvement in sarcoidosis is seen in $25 \%$ of cases and is most often noted at the onset of the disease process [5-7]. In this study we describe clinical and pathological findings of 15 cases with biopsy confirmed cutaneous sarcoidosis. The mean age at diagnosis was 46 years with female preponderance, which is similar to previous studies [7-9,14].

Cutaneous manifestations are diverse however, the most common presentations involve erythematous to brown papules, plaques and nodules [6]. However, in our series the most common presentation was that of nodules. This is in contrast with most of the studies which showed maculopapular eruptions to be the commonest presentation $[5,6,15]$. Subcutaneous nodules were more frequently seen in females than in male patients. Subcutaneous nodules have also been suggested as an adverse prognostic subtype but as the data in present study regarding presence of extra-cutaneous disease is not available, so this cannot be commented upon $[14,16]$. Facial involvement was around $25 \%$ cases of cutaneous sarcoidosis in most studies compared to $33.3 \%$ in our study $[8,9]$.

With respect to microscopic findings, naked sarcoidal granulomas (NSG) were seen in $86.7 \%$ cases, confirming this feature as a sensitive and characteristic histologic finding in cutaneous sarcoidosis [6,8]. Reticulin rich NSG were seen in $100 \%$ of the cases [17]. Extensive superficial and deep infiltrate of the dermis was the most common infiltrating pattern.

A range of conditions from infectious processes to reactions to foreign material can show NSG in biopsy but it can be differentiated by clinical findings and special stains.

Recent studies have demonstrated the presence of foreign particles within cutaneous granulomatous lesions in patients with well-established systemic sarcoidosis $[6,7,18]$. One case in our study showed the presence of foreign body at the site of tattoo which support the hypothesis that foreign material may serve as a nidus for granuloma formation in sarcoidosis. Some studies demonstrated that sarcoidosis can arise in scars, tattoos, surgery or due to long term trauma $[5,7,15,19,20]$. The clinical presentation of our cases did not appear to significantly differ from typical cases of sarcoidosis, because clinically sarcoidosis diagnosis was also suspected, and confirmed on biopsy.

We found focal fibrinoid necrosis in $13.3 \%$ of cases which is comparable with other studies available [7,8]. Focal necrobiosis associated with granulomas were present in two cases but with clinical correlation, sarcoidosis was considered to be the most likely diagnosis in them.

Asteroid and/or Schaumann bodies were found in only $20 \%$ of the biopsies and are considered less sensitive marker for sarcoidosis. Previous studies also indicate that they are a relatively non-specific finding [21,22]. Mimickers like tuberculosis, leprosy and other infectious causes were ruled out by special stains like reticulin, AFB, PAS and Wade-Fite stain along with correlation of the clinical findings The granulomas in sarcoidosis cases showed reticulin stain positivity. In our series we did not find any peri-neural granulomas.

\section{Conclusion}

The clinical presentation of cutaneous sarcoidosis may be variable. Sarcoidosis should be considered in any patient whose skin biopsy demonstrates granulomatous inflammation without an apparent primary cause. Presence of naked, reticulin rich granulomas is the most characteristic histopathological feature in cutaneous sarcoidosis. Histopathology with clinical history may help reach to a conclusive diagnosis.

\section{References}

1. Iannuzzi MC, Fontana JR. Sarcoidosis: clinical presentation, immunopathogenesis, and therapeutics. JAMA. 2011;305:391-399.

2. Hosoda Y, Yamaguchi M, Hiraga Y. Global epidemiology of sarcoidosis. What story do prevalence and incidence tell us? Clin Chest Med. 1997;18: 681-694.

3. Rybicki BA, Maliarik MJ, Major M, Popovich J Jr, Iannuzzi MC. Epidemiology, demographics, and genetics of sarcoidosis. Semin Respir Infect. 1998;13:166-173.

4. Marchell RM, Thiers B, Judson MA. Sarcoidosis. In: Wolff K, Goldsmith LA, Katz SI, Gilchrest BA, Paller AS, Leffell DJ, eds. Fitzpatrick's dermatology in General Medicine. 7th ed. McGraw-Hill, New York, 2008: pp. 1484-1493.

5. Mañá J, Marcoval J, Graells J, Salazar A, Peyrí J, Pujol R. Cutaneous involvement in sarcoidosis. Relationship to systemic disease. Arch Dermatol. 1997;133:882-888.

6. English JC 3rd, Patel PJ, Greer KE. Sarcoidosis. J Am Acad Dermatol. 2001;44:725-743.

7. Mangas C, Fernández-Figueras MT, Fité E, Fernández-Chico $\mathrm{N}$, Sàbat $\mathrm{M}$, Ferrándiz C. Clinical spectrum and histological analysis of 32 cases of specific cutaneous sarcoidosis. J Cutan Pathol. 2006;33:772-777.

8. Ball NJ, Kho GT, Martinka M. The histologic spectrum of cutaneous sarcoidosis: a study of twenty-eight cases. J Cutan Pathol. 2004;31:160-168.

9. Cardoso JC, Cravo M, Reis JP, Tellechea O. Cutaneous sarcoidosis: a histopathological study. J Eur Acad Dermatol Venereol. 2009;23:678-682.

10. Sharma OP. Sarcoidosis of the skin. In: Freedberg IM, Fitzpatrick TB, eds. Fitzpatrick's Dermatology in General Medicine, 5th ed. McGraw- Hill, New York, 1999: pp. 2099-2106.

11. Shetty A, Gedalia A. Sarcoidosis. Available from: http:// www.emedicine.com/ped/topic2043.html [Accessed 2015 Jan15].

12. Braun-Falco O, Plewig G, Wolff HH, Burgdorf WHC, Landthaler M. Granulomatise Erkrankungen. In: Goerdt S, ed. Dermatologie und Venerologie 5 Auflage, Springer, Heidelberg. 2005: pp. 523-536. 
13. Johns CJ, Michele TM. The clinical management of sarcoidosis. A 50-year experience at the Johns Hopkins Hospital. Medicine (Baltimore). 1999;78:65-111.

14. Collin B, Rajaratnam R, Lim R, Lewis H. A retrospective analysis of 34 patients with cutaneous sarcoidosis assessed in a dermatology department. Clin Exp Dermatol. 2010;35:131-134.

15. Olive KE, Kataria YP. Cutaneous manifestations of sarcoidosis. Relationships to other organ system involvement, abnormal laboratory measurements, and disease course. Arch Intern Med. 1985;145:1811-1814.

16. Ahmed I, Harshad SR. Subcutaneous sarcoidosis: is it a specific subset of cutaneous sarcoidosis frequently associated with systemic disease? J Am Acad Dermatol. 2006;54:55-60.

17. Mitchell DN, Scadding JG, Heard BE, Hinson KF. Sarcoidosis: histopathological definition and clinical diagnosis. J Clin Pathol. 1977;30:395-408.
18. Ferrara G, Cannone M, Scalvenzi M, Delfino M, Staibano S, De Rosa G, et al. Facial granulomatous diseases: a study of four cases tested for the presence of Mycobacterium tuberculosis DNA using nested polymerase chain reaction. Am J Dermatopathol. 2001;23:8-15.

19. Hanno R, Needelman A, Eiferman RA, Callen JP. Cutaneous sarcoidal granulomas and the development of systemic sarcoidosis. Arch Dermatol. 1981;117:203-207.

20. Yanardağ H, Pamuk ON, Karayel T. Cutaneous involvement in sarcoidosis: analysis of the features in 170 patients. Respir Med. 2003;97:978-982.

21. Reid JD, Andersen ME. Calcium oxalate in sarcoid granulomas. With particular reference to the small ovoid body and a note on the finding of dolomite. Am J Clin Pathol. 1988;90:545-558.

22. Kim YC, Triffet MK, Gibson LE. Foreign bodies in sarcoidosis. Am J Dermatopathol. 2000;22:408-412. 